\title{
Aquisição da linguagem e inclusão educacional Estratégias educacionais entre cegos deficientes múltiplos
}

\section{Language acquisition and educational inclusion: Educational strategies among multiple disabled blinds}

\author{
Maria Vitoria Campos Mamede Maia* Maria do Socorro Fortes de Oliveira **, Cláudia Monserrat Rosa de Oliveira \\ Fontoura*** \\ *Universidade Federal do Rio de Janeiro (UFRJ), ** UFRJ / Instituto Benjamin Constant (IBC), *** Universidade Federal do Rio de \\ Janeiro (UFRJ)
}

\begin{abstract}
Resumo
Esta pesquisa versa sobre a aquisição da linguagem e a inclusão educacional de sujeitos cegos deficientes múltiplos. O objetivo foi analisar como três instrumentos, criados para que educadores dos primeiros anos do Ensino Fundamental do Instituto Benjamin Constant, poderiam facilitar o desenvolvimento da comunicação oral e inclusão dos alunos cegos deficientes múltiplos. Esta pesquisa é qualitativa, do tipo etnográfico, teve como sujeitos dois adolescentes. A análise dos resultados baseou-se na metodologia bardiniana, apontou o desenvolvimento da linguagem e interação entre os pares, permitindo sua inclusão em turma regular.

Palavras-Chave: inclusão educacional, jogos e brincadeiras, aquisição da linguagem, cegos deficientes múltiplos.
\end{abstract}

\begin{abstract}
This research deals with the language acquisition and the educational inclusion of multiple disabled blind people. The aim was to analyze how three instruments, created so that early childhood educators of the Benjamin Constant Institute could help oral communication and inclusion of blind students with multiple disabilities. The qualitative research, of the ethnographic type, had as subjects two adolescents. The analysis of the results used the bardinian method, and pointed out the development of language and interaction between the pairs, allowing the inclusion in a regular class.
\end{abstract}

Keywords: games and games, language acquisition, multiple handicapped blinds, educational inclusion

Este trabalho versa sobre uma prática para facilitar a socialização e comunicação oral de alunos cegos deficientes múltiplos. $O$ relato de pesquisa que se apresenta neste artigo faz parte de uma pesquisa maior, "Criatividade e Educação: diferentes linguagens habitando o espaço educacional” (MAIA, 2016), na qual se estuda a importância do lúdico no processo de ensino-aprendizagem. Utilizaram-se jogos e brincadeiras do cotidiano dos alunos do Instituto Benjamin Constant (IBC), cegos com deficiência múltipla, sendo esses instrumentos um recurso pedagógico cujo uso pretende-se que se estenda para além dos muros escolares, corroborando para a autonomia dos referidos sujeitos. Acredita-se que o compartilhamento e a difusão destes recursos serão de utilidade entre familiares, cuidadores e educadores de alunos com esse perfil.

A prática pedagógica desenvolvida entre alunos deficientes múltiplos que estudam no Instituto Benjamin Constant, até o ano de 2016, era baseada no Modelo Ecológico Funcional. O objetivo deste era proporcionar oportunidades para o pleno desenvolvimento dos alunos, facilitando sua autonomia, inclusão, participação em seu grupo social, que inclui sua família, escola e comunidade no qual está inserido (JESUS, 2017). Acrescenta-se, ainda, que uma das principais metas visava o desenvolvimento de habilidades relevantes à vida diária do aluno. Desde o início do ano de 2017, o Instituto Benjamin Constant, onde essa pesquisa foi realizada, vem reestruturando seu ambiente educacional, ampliando-o para atender o crescente número de matrículas de alunos com deficiência múltipla associada à cegueira.

O comprometimento da visão e da comunicação oral pode representar um fator determinante na dissocialização dos indivíduos deficientes, se fazendo necessária uma ação transformadora para minimizar esse transtorno. Nunes (2003) informa que a comunicação feita por meio da linguagem representa o mais importante processo no desenvolvimento humano. Assumpção \& Valle (2008) comungam com esta ideia quando dizem que, além de a linguagem ser um instrumento de comunicação, ela contribui para a organização do pensamento, facilitando a transmissão de ideias, informações e comunicação de sentimentos.

Com base nestas reflexões, surgiu a problemática deste estudo: a utilização de práticas pedagógicas como jogos e brincadeiras podem ser utilizadas para melhorar a socialização e comunicação oral de cegos deficientes múltiplos? O objetivo deste trabalho foi analisar como três instrumentos, criados para que educadores dos 
primeiros anos do Ensino Fundamental do Instituto Benjamin Constant, poderiam facilitar o desenvolvimento da comunicação oral e a inclusão dos alunos cegos com deficiência múltipla

Para fundamentar esse estudo, tomou-se como base, entre outros autores, Glat \& Pletsch (2013), que enfatizam a importância da utilização de um Plano Educacional Individualizado para atender as especificidades destes alunos; Kirk \& Gallagher (2002), cuja obra inspira adaptações específicas para deficientes múltiplos com uma proposta de atendimento inclusivo. Igualmente reportou-se a Nunes (2003), que desenvolve pesquisas inovadoras voltadas para investigações comunicativas de jovens com necessidades especiais, a importância da utilização de recursos apropriados para atender às dificuldades de comunicação oral, entre outras possibilidades; Siaulys (2010), cujas experiências relatadas, serviram como exemplo para o enriquecimento da prática educativa que objetiva o ensino e o processo de aprendizado.

No atual cenário educacional, vivencia-se um momento que exige do educador a utilização de estratégias que facilitem o processo de aprendizagem, contemplando e respeitando, sobretudo, as diferentes maneiras de aprender de cada indivíduo, principalmente daqueles que apresentam deficiência múltipla (GLAT \& PLETSCH, 2013). Diante das inúmeras diferenças no processo de ensino-aprendizagem desse alunado, pretende-se, neste trabalho, apresentar a utilização dos jogos e brincadeiras como recursos possíveis para promover a socialização e a comunicação oral, material este que requer adaptações individualizadas para que os mesmos sejam utilizados em prol do aprendizado destes alunos.

\section{Cegueira}

Considera-se importante entender um pouco sobre a cegueira para o pleno desenvolvimento da proposta de trabalho com estudantes cegos com deficiência múltipla. Uma deficiência, cuja maior característica é a de privar a identificação e delimitação visual da forma de objetos que estão presentes no mundo da maioria dos videntes, dificultando a interação social. Martín \& Bueno (2003), afirmam que é considerado cego o indivíduo com ausência total de visão ou simples percepção luminosa que faz uso dos sentidos remanescentes e é usuário do Sistema Braille. Os mesmos autores, salientam que o aprendizado da criança cega é semelhante ao da normovisual, que aprende experimentando, olhando, sentindo. Entretanto, pela falta da visão, não tem como perceber os detalhes. Por isso, há a necessidade de experiências táteis para a concretude do aprendizado,

\section{Deficiente Múltiplo}

A deficiência Múltipla é uma expressão utilizada para designar as pessoas que apresentam duas ou mais deficiências primárias (mental/visual/auditiva/física) associadas, afetando mais ou menos intensamente, o funcionamento do indivíduo inclusive seu relacionamento social, com comprometimentos que acarretam atrasos no desenvolvimento global e na capacidade adaptativa dos mesmos (PLETSCH, 2015;
BOATO, 2009; CARVALHO, 2000). Kirk \& Gallagher (2002) acrescentam que deficiente múltiplo é aquele que possui mais de uma deficiência considerada moderada ou grave, necessitando de atenção diferenciada e especial para que sejam minimizadas ou superadas suas limitações.

Trabalhar com esse grupo de deficientes é um desafio para qualquer profissional, pois as propostas de intervenção pedagógica precisam ser adaptadas às peculiaridades individuais. Nesse contexto, a importância do oferecimento de atividades funcionais e experiências significativas, por meio de estratégias diferenciadas e formas alternativas de comunicação, adequadas às especificidades de cada aluno devem ser enfatizadas, tornando possível a obtenção de resultados pedagógicos favoráveis. Deste modo, é de suma importância que a Comunicação Alternativa seja utilizada por mediadores sempre atentos e interessados em se comunicar com o aluno que não utiliza a fala oral articulada (PELOSI, in NUNES, SUPLINO \& WALTER, 2013).

\section{Comunicação Alternativa}

$\mathrm{Na}$ Comunicação Alternativa são utilizados diversos recursos, que inclusive podem ser confeccionados com materiais de baixo custo ou baixa tecnologia (PLETSCH, 2015). É comum fazer uso de gestos manuais, expressões faciais e corporais, símbolos gráficos bidimensionais e tridimensionais, voz digitalizada ou mesmo sintetizada entre outros recursos, desde que facilitem a comunicação entre todos aqueles que não possam se comunicar oralmente, por meio da linguagem (NUNES, 2003). Ressalta-se que a linguagem é considerada um modo privilegiado para a aquisição de sistemas simbólicos e desenvolvimento de habilidades de relacionamento interpessoal. Assim, quando a criança se encontra impedida de estabelecer a comunicação por meio da linguagem, muitos aspectos de seu desenvolvimento são afetados (NUNES, 2003).

Nesse sentido, a escolha de jogos e brincadeiras parece ser uma opção favorável ao incentivo à comunicação e socialização destes estudantes.

\section{Jogos e brincadeiras}

Se neste trabalho se defende a utilização de jogos e brincadeiras para o processo de aquisição da linguagem por esse alunado, deve-se, neste momento, ser conceituado o que sejam jogos e brincadeiras no âmbito deste artigo.

Os jogos carregam em seu bojo possibilidades que contribuem para o exercício das funções cognitivas e afetivas dos sujeitos (MAIA, 2014). Podem incluir atividades do cotidiano e, consequentemente, estimular o desenvolvimento das relações interpessoais, principalmente quando praticados em grupo (VISCA, 2009).

Os jogos possibilitam diversas oportunidades para que se trabalhe o limite, a criatividade, a partilha e a intermediação. Com esses instrumentos, proporciona-se aos alunos oportunidades de aprenderem a desafiar a si mesmas e vivenciarem momentos de perda e ganho (MAIA, 2014). Acrescenta-se, ainda, que, a partir os 
jogos propostos na pesquisa aqui relatada, utilizados como instrumentos de trabalho docente, propiciaram aos alunos cegos, de modo lúdico, a aprendem a nomear, a se deslocar, localizar, simbolizar situações do cotidiano, criar atalhos, perceber detalhes e a memorizar. A cada vez em que é jogado pode-se adquirir uma faceta da sociabilidade e da comunicabilidade. Tal aprendizado é um processo lento, gradual.

As brincadeiras são um tipo de linguagem e a primeira forma de cultura. A mesma cultura que a todos pertence e por isso, faz com que todos participem de ideias e objetivos comuns (MEYER, 2011). As brincadeiras devem ocupar um lugar de destaque no ambiente escolar. Ressalta-se que, para o deficiente, é um recurso que se sobressai, pois, além de ser uma atividade prazerosa, trata-se de uma excelente oportunidade para facilitar a ação sobre objetos e ambiente, proporcionando momentos de vivências, experiências necessárias ao desenvolvimento da comunicação e à própria socialização do cego deficiente múltiplo (SIAULYS, 2010).

Para tanto, é necessário que o aluno esteja envolvido em um ambiente de segurança, proporcionado principalmente pelo professor em sala de aula, para sentir-se seguro a ponto de ter confiança nele próprio e nas demais pessoas que o cercam. Cabe salientar a importância do brincar, e ao mesmo tempo, reafirmar que é possível aprender brincando, e que brincando, aprendemos a viver. Winnicott $(1975$, p. 147) diz que "(...) o brincar conduz naturalmente à experiência cultural e, na verdade, constitui seu fundamento". Assim, é viável considerar que o ambiente é repleto de possibilidades que contribuem para o aprendizado e por meio da brincadeira o aluno pode assumir papéis, revelando um víeis para o aprendizado de regras tão importantes para a inclusão educacional de alunos cegos deficientes múltiplos (MEYER, 2011).

\section{A pesquisa}

A metodologia utilizada foi a pesquisa qualitativa de viés etnográfico (GLAT \& PLETSCH, (2011), ANDRÉ (2012), MALHEIROS (2011).

O trabalho foi realizado com dois adolescentes com idade de treze e dezesseis anos, matriculados simultaneamente no primeiro ano do Ensino Fundamental e no Programa Educacional Alternativo do Instituto Benjamin Constant. Esses alunos possuíam um programa educacional individualizado, com atividades que beneficiavam o relacionamento interpessoal dos alunos, sua comunicação, incluindo também atividades específicas para deficientes visuais, além de outras habilidades necessárias à sua socialização e aprendizagem. Eram alunos que apresentavam defasagem em seu desenvolvimento global, necessitando de atenção especial à sua diversidade, seus processos psicológicos, participação dinâmica nos ambientes e principalmente sua construção sociocultural (BRONFENBRENNER, 2002).

A pesquisa aqui relatada foi realizada em 2016, durante cinquenta minutos, duas vezes por semana. Ao longo deste período, após a identificação das singularidades e prioridades a serem contempladas, era oferecido um jogo ou uma brincadeira era proposta. As regras e funcionamento destes eram explicados e detalhados.

Como os jogos e brincadeiras propostos possuíam uma intenção pedagógica, educativa e de aprendizagem, os alunos eram observados não somente durante os jogos, mas, posteriormente, ao executarem tarefas em seu próprio ambiente, escola, ou mesmo alguma informação de que um determinado conceito ou comportamento foi adquirido.

Os jogos e brincadeiras eram adaptados às peculiaridades dos alunos, de modo a atender as necessidades individualizadas como, por exemplo, foram empregados como atividades lúdicas na construção de maquetes em busca de novos estímulos para desenvolver a Comunicação e Socialização dos mesmos. Os sujeitos eram encorajados a percorrer as maquetes por meio da coordenação motora fina e, em seguida, executar o seu trajeto real para vivenciar a rotina do ambiente escolar, o percurso de sala de aula, sanitários, refeitório, biblioteca, orientação espaço temporal na entrada e saída da escola, entre outros espaços normalmente percorridos por cada um.

Os mesmos alunos eram também estimulados a relatar os trajetos percorridos e esta vivência contribuiu para organizar o seu pensamento, estimular a comunicação e relações interpessoais entre eles, principalmente quando eram levados a explorar, questionar, desvendar algum espaço ou fato e até levantar hipóteses sobre alternativas em seus percursos, utilizando fatos do dia-a-dia como por exemplo: em dia de chuva qual o percurso seria utilizado. Essas atividades foram registradas, descrevendo a atividade e os objetivos trabalhados, alcançados ou não.

Os resultados foram registrados, como positivos ou negativos, em uma planilha contendo itens simples apenas para facilitar a identificação do jogo, se o grau de dificuldade tinha sido apropriado para o aluno e a avaliação dos resultados apresentados.

Por fim, foi elaborado um fichário contendo jogos pedagógicos, a partir do campo de pesquisa, sendo este a síntese do trabalho efetuado com os alunos sujeitos desta pesquisa. O fichário possuía um conteúdo funcional, tendo sido confeccionado com baixo custo, pôde servir de instrumento para auxiliar e estimular os alunos na aquisição e fixação de conceitos utilizados na conversação socialização entre seus pares. Neste havia o nome do jogo; descrição dos mesmos com suas regras; material utilizado para a confecção, objetivos a serem atingidos. As brincadeiras foram adaptadas ou criadas; tal como os jogos, incluía o nome da brincadeira, a descrição de como brincar, material utilizado, inclusive sugestão de ilustrá-las tridimensionalmente ou com objetos concretos, ou feita áudio descrição para facilitar a imaginação e a compreensão das mesmas.

Foi escolhido para a intervenção com os alunos A e B dois jogos e uma brincadeira. Na confecção do Jogo 1, denominado "Jogo O bolo da vovó", foi utilizado pranchas com miniaturas coladas em cartões, devidamente identificadas, ou ainda peças dispostas em uma caixa para serem identificadas e escolhidas. $\mathrm{O}$ procedimento deste jogo é cada aluno pegar a peça 
correspondente à proposta do Bolo da Vovó, a partir da fala do professor, criando o cenário para o mesmo. $\mathrm{O}$ professor inicia dizendo: "Para fazer um bolo na casa da vovó nós utilizamos: colher de pau, pão duro e....". Ganha o jogo quem conseguir juntar o maior número de utensílios e avisar ao grupo a quantidade e enumerar cada utensílio. Neste jogo, trabalha-se a rapidez, comunicação, interação, atenção, operações matemáticas, orientação espacial.

O Jogo 2, denominado "Bola cheia", continha bolas de aniversário, coloridas e cheias, e o objetivo era fazer com que os alunos conseguissem manter o maior número de bolas cheias na mão esquerda. A um sinal emitido pelo professor, os alunos procuram correr até os colegas, identificando sua direção por meio do som produzido por uma pulseira com guizos. Quando encontram o colega, tentam explodir as bolas que estão em sua mão direita e dizem: - essa bola é minha. $O$ professor interrompe o jogo com um sinal sonoro e as bolas são contadas. Ganha o aluno que mantiver o maior número de bolas cheias na mão direita

Já a brincadeira partiu de dois personagens idealizados pelos próprios alunos, fazendo alusão a seus irmãos, nomeados de Daniel e Karina. A partir de um bonecomanequim, com aparência aproximada de uma criança de sete anos de idade, com 1 metro de altura, cabeça e membros articulados e com aspecto masculino ou feminino, de acordo com a brincadeira, os alunos eram estimulados a falar sobre gênero, esquema corporal, percepção, organização coletiva para o desenvolvimento de uma brincadeira, individual ou em grupo. Os alunos foram estimulados a falar sobre seu próprio corpo e, posteriormente, se orientar e se movimentar organizadamente em torno de outros colegas da sala ou do ambiente escolar, relatando alguns momentos mais significativos para cada um.

\section{Análise e resultados da Pesquisa}

No início da pesquisa, os alunos não conseguiam transitar com liberdade e autonomia na sala de aula e precisavam de auxílio para chegar aos ambientes de suas necessidades básicas. Opunham-se ao novo, quando lhes era proposta alguma atividade mesmo que individualmente, não demonstravam interesse para fazer escolhas, quando lhes era oferecida uma ou outra atividade como opção; não possuíam iniciativa para atividades escolares ou de lazer, nem facilidade em se relacionar com os demais colegas. Além disso, apresentavam dificuldades em se comunicar oralmente, de aceitar normas escolares. Se houvesse insistência no cumprimento de alguma atividade proposta, os alunos ofereciam resistência, mesmo para aquelas consideradas do dia-a-dia escolar, como por exemplo, dirigir-se a um ambiente, organizar materiais utilizados, fazer higiene após a utilização de colas ou tintas e ainda demonstravam não ter vontade para cumprir hábitos sociais durante diversos momentos de convívio com os demais colegas, principalmente em horário de lanches e refeições.

$\mathrm{O}$ adolescente A era assíduo, mas totalmente dependente, não formulando frases completas e coerentes para se comunicar oralmente. Mostrava-se bastante resistente às atividades escolares e interpessoais. Negava-se a executar tarefas propostas mesmo as mais simples. A partir dos jogos e brincadeiras sugeridas, iniciou seu interesse em participar de atividades em sala de aula ou nos ambientes externos juntamente com outros colegas ou familiares. Gradativamente, passou a se locomover nos ambientes familiares e da escola, demonstrando segurança em fazê-lo no seu ir e vir exitoso. Aos poucos, deu-se início a uma nova fase em sua comunicação. Esta passou a ser feita por meio de frases inicialmente curtas, mas elaboradas, coerentes e contextualizadas. Posteriormente, aumentou a utilização de seu vocabulário, inserido em sua conversação algumas palavras novas e contextualizadas; além disso, passou a demonstrar satisfação ao perceber o êxito de sua comunicação, uma vez que suas solicitações eram atendidas e seus familiares o premiavam com guloseimas e o mimavam com presentinhos. Passou a relacionar-se com os colegas, aceitando auxílio em sua locomoção, respondendo de algum modo aos questionamentos que os próprios colegas faziam; também passou a aceitar melhor os alimentos oferecidos e utilizar o vestuário autonomamente após atividades físicas, partilhando e compartilhando seus pertences; demonstrava interesse em ser inserido no processo de ensino aprendizagem perante alguma atividade em sala, procurando e aceitando a participação de outros colegas consigo.

O aluno B possuía uma relativa autonomia. Ele transitava nos espaços da escola, mas não raro esquecia para onde ia e o que iria fazer; não se expressava oralmente e havia necessidade de ser questionado para elaborar respostas, completar sua intenção comunicativa e de se desenvolver psicolinguisticamente; ainda não era alfabetizado e precisava ser motivado à aprendizagem. Paulatinamente, passou a questionar as atividades e a necessidade de executar as mesmas, demonstrando interesse para concluí-las.

A escolha e utilização desses dois jogos e dessa brincadeira mostraram-se ser um suporte efetivo para esse aluno. Foi possível observar a melhora em sua comunicação, maior facilidade para expressar suas ideias e socialização. Percebeu-se, ao longo desse processo, que a ansiedade presente no cumprimento de atividades foi sendo substituída pelo prazer das descobertas de suas possibilidades e sua aceitação no grupo.

\section{Conclusão}

O desenvolvimento do presente estudo possibilitou uma análise da importância da utilização de Jogos e Brincadeiras para facilitar a socialização e comunicação oral de alunos cegos Deficientes Múltiplos.

A experiência vivenciada em sala de aula mostrou-se vantajosa, importante e necessária na prática pedagógica. Os alunos pesquisados possuíam baixa autoestima; apresentavam dificuldades em organizar seus pensamentos, se comunicar, locomover, interagir com outros colegas; possuíam necessidade de aprender 
conceitos básicos, de higiene e orientação espacial, que resultavam em dificuldades para sua inclusão educacional e social. Com a utilização desses recursos, foi possível perceber a importância de diversificar e ousar em artifícios simples, uma vez que cada atividade lúdica vivenciada facilitou a obtenção de resultados harmônicos em sua aprendizagem.

Portanto, fica evidente, diante desses resultados, que os jogos, associados às brincadeiras com sua vertente lúdica, cognitiva, social e psicológica, forneceram aos alunos um ambiente enriquecedor $\mathrm{e}$ motivador, que ultrapassou a função de só divertir. A utilização de jogos e brincadeiras contribuiu visivelmente para o desenvolvimento de habilidades gerando resultados expressivos a favor da aprendizagem, ao possibilitar a vivência da socialização e da comunicação nas atividades. Outro aspecto percebido deste processo aqui relatado foi a aquisição da memorização de alguns conceitos que antes não haviam assimilado. Essa conquista foi feita por meio de um processo de criação próprio, marcando o início da autonomia diante do aprender, levando os alunos a revisarem e até reforçar o aprendizado adquirido no ambiente educacional.

\section{Referências}

André, Marli Eliza Dalmazo Afonso de. Etnografia na Prática Escolar. 18ed. Campinas: Papirus. 2012. (Série Pedagógica).

Assumpção, Francisco Baptista, \& VALLE, Luiza Elena Leite Ribeiro do. (Orgs.) Aprendizagem, linguagem e pensamento. Rio de Janeiro: Wak Ed. 2008. (neuropsicologia aplicada; v. 1).

Boato, Elvio Marcos. Henri Wallom e a Deficiência Múltipla: uma proposta de intervenção pedagógica. São Paulo: Loyola, 2009.

Bronfenbrenner, Urie. A ecologia do desenvolvimento humano: experimentos naturais e planejados. [Tradução Maria Adriana Veríssimo Veronese]. 2 Reimpressão. Porto Alegre: Artes Médicas, 2002.

Carvalho, Erenice Natália Soares de. Programa de Capacitação de Recursos Humanos do Ensino Fundamental: Deficiência Múltipla Vol. 1. Fascículos I - II - III. Brasília: Ministério da Educação, Secretaria de Educação Especial, 2000. (Série Atualidades Pedagógicas 5). Disponível em: http://portal.mec.gov.br/seesp/arquivos/pdf/def_multi pla_1.pdf. Acesso em: 28 fev. 2017.

Glat, Rosana, \& Pletsch, Marcia Denise. Inclusão escolar de alunos com necessidades especiais. Rio de Janeiro: Editora da Universidade do Estado do Rio de Janeiro 2011.

Glat, Rosana, \& Pletsch, Marcia Denise (Organizadoras). Estratégias diferenciadas para alunos com necessidades especiais. Rio de Janeiro: EdUERJ, 2013.

Jesus, Elisabeth Ferreira. Deficiência Múltipla e o Modelo Ecológico Funcional. Disponível em: http://www.ibc.gov.br/educacao-basica/prea - Acesso em: 27 fev. 2017.
Kirk, Samuel Alexander \& Gallagher, James J. Educação da Criança Excepcional. 3. ed. [Tradução Marília Zanella Sanvicente]. São Paulo: Martins Fontes Editora Ltda. 2002.

Maia, Maria Vitória Campos Mamede. Criar e brincar: o lúdico no processo de ensino e aprendizagem. Rio de Janeiro: Wak Editora, 2014.

Malheiros, Bruno Taranto. Metodologia da pesquisa em educação. Rio de Janeiro: LTC, 2011.

Martín, Manuel Bueno \& Bueno, Salvador Toro. Deficiência Visual: aspectos psicoevolutivos e educativos. [Trad. Magali de Lourdes Pedro]. São Paulo: Santos, 2003.

Meyer, Ivanise Corrêa Rezende. Brincar e viver: projetos em educação infantil. 5ed. Rio de Janeiro: Wak Editora, 2011.

Nunes, Leila Regina d'Oliveira de Paula (Org.). Favorecendo o desenvolvimento da comunicação em crianças e jovens com necessidades educacionais especiais. Rio de Janeiro: Qualitymark Editora Ltda. 2003.

Pletsch, Márcia Denise. Multiple disabilities: teacher training and teaching-learning processes. Cad. Pesqui., São Paulo, v. 45, n. 155, p. 12-29, mar. $2015 . \quad$ Disponível em: http://www.scielo.br/scielo.php?script=sci_arttext\&pi $\mathrm{d}=$ S0100-15742015000100012\&lng=pt\&nrm=iso.
Acesso
em:
01 Abr.
2017. http://dx.doi.org/10.1590/198053142862. Acesso em: 01 Abr 2017.

SIAULYS, Mara Olímpia De Campos \& ORMELEZI, Eliana Maria \& BRIANT, Maria Emília (orgs.), A deficiência visual associada à deficiência múltipla e o atendimento educacional especializado. Encarando desafios e construindo possibilidades. São Paulo: Laramara, 2010.

Visca, Jorge. Introducción a los juegos lógicos en el tratamento psicopedagógico. Buenos Aires: Visca \& Visca, 2009.

Winnicott, Donald Woods. O Brincar \& a Realidade, Rio de Janeiro: Imago editora, 1975. (Coleção Psicologia Psicanalítica). 